\title{
Electrochemical fouling of dopamine and recovery of carbon electrodes
}

Emilia Peltola ${ }^{1,2 *}$, Sami Sainio ${ }^{1}$, Katherine B. Holt ${ }^{2}$, Tommi Palomäki ${ }^{1}$, Jari Koskinen ${ }^{3}$, Tomi Laurila ${ }^{1}$

1 Department of Electrical Engineering and Automation, School of Electrical Engineering, Aalto University, Espoo, Finland

${ }^{2}$ Department of Chemistry, University College London, London, UK

${ }^{3}$ Department of Chemistry and Materials Science, School of Chemical Engineering, Aalto University, Espoo, Finland

* Corresponding author: Tel: +358 50435 4505, email: emilia.peltola@aalto.fi 


\begin{abstract}
A significant problem with implantable sensors is electrode fouling, which has been proposed as the main reason for biosensor failures in vivo. Electrochemical fouling is typical for dopamine (DA) as its oxidation products are very reactive and resulting polydopamine has a robust adhesion capability to virtually all types of surfaces. The degree of DA fouling of different carbon electrodes with different terminations was determined using cyclic voltammetry $(\mathrm{CV})$ and scanning electrochemical microscopy (SECM) approach curves and imaging. The rate of electron transfer kinetics at the fouled electrode surface was determined from SECM approach curves allowing a comparison of insulating film thickness for the different terminations. SECM imaging allowed the determination of different morphologies, such as continuous layers or islands, of insulating material. We show that heterogeneous modification of carbon electrodes with carboxyl-amine functionalities offers protection against formation of an insulating polydopamine layer, while retaining the ability to detect DA. The benefits of the heterogenous termination are proposed to be due to the electrostatic repulsion between aminofunctionalities and DA. Furthermore, we show that the conductivity of the surfaces as well as the response towards DA was recovered close to the original performance level after cleaning the surfaces for 10-20 cycles in $\mathrm{H}_{2} \mathrm{SO}_{4}$ on all materials but pyrolytic carbon (PyC). The recovery capacity of PyC electrode was lower possibly due to stronger adsorption of DA on the surface.
\end{abstract}




\section{Introduction}

Neuronal communication in the brain relies on precisely controlled dynamics of neurotransmitters, the molecules that are used for neuron-to-neuron signalling. Consequently, several diseases of the brain either are due to or associated with changes in the spatial and temporal kinetics of the neurotransmitters. One important neurotransmitter is dopamine (DA), which is involved in a variety of brain disorders such as schizophrenia and addictions as well as in Parkinson's disease, where the brain DA neurons are degenerating ${ }^{1}$. The accurate measurement of DA would provide a better understanding of these diseases and a tool to follow up the output of the treatments. Electrochemical techniques provide a cheap method that is compatible in vivo for the real-time detection of DA.

A significant problem with this type of technique is electrode fouling, which has been proposed as the main reason for biosensor failure in vivo ${ }^{2}$. The electrode fouling is the consequence of two main mechanisms, which both have to be addressed. 1) Biofouling is the passive adherence of background species, such as proteins or lipids, to the electrode surface. 2) Electrochemical fouling means the formation of an insulating film on the electrode as a sequence of the reaction used for the detection. This electrochemical fouling is typical for DA as its oxidation products are very reactive. Under proper environment $(\mathrm{pH}>7.5$, DA concentrations higher than $2 \mathrm{mg} / \mathrm{mL}$ ), polydopamine formation occurs spontaneously ${ }^{3}$.

The reaction pathway leading to DA fouling is shown in Figure 1. The first step in DA oxidation into dopamine ortho-quinone (DAQ) involves a two-electron transfer accompanied with deprotonation. In the second step the DAQ undergoes intramolecular cyclization via 1,4 Michael addition which leads to the formation of leucodopaminechrome (LDAC) ${ }^{4}$. LDAC is further oxidized in a two-electron transfer to dopaminechrome (DAC), which may further go polymerization process and form polydopamine on the electrode. The molecular mechanism behind the formation of polydopamine is still of scientific debate, and several mechanisms have been proposed (reviewed in ${ }^{3}$ ). Because of the complex redox process as well as the generation of a series of intermediates during the polymerization and reaction processes, many functional groups including planar indole units, amino group, carboxylic acid group, catechol or quinone functions, and indolic/catecholic $\pi$-systems are integrated into polydopamine ${ }^{5}$. Consequently, polydopamine has a robust adhesion capability to virtually all types of surfaces ${ }^{3}$. This polydopamine formation results in signal attenuation and compromises the quality of the measurements, as the thick layer may prevent or hinder electron transfer. Moreover, the electrochemical oxidation of neurotransmitters is typically an inner-sphere reaction involving surface adsorption ${ }^{6}$, which may be blocked by the fouled layer.

This paper investigates electrochemical fouling of DA on different carbon-based electrode materials. Carbon thin films such as amorphous carbon (a-C), tetrahedral amorphous carbon (ta-C) and pyrolytic carbon are patternable and relatively cheap and easy to deposit on nearly any given surface. In comparison to metal films, a-C and ta-C films have the advantage of low fabrication temperatures. Carbon is also abundant and will therefore never become a critical material. Moreover, a-C and ta-C are completely CMOS-compatible. Both a-C and ta-C have good electrochemical properties such as a large water window and a low background signal, which makes them highly attractive for electroanalytical chemistry ${ }^{7}$. There are several articles reporting their qualities as sensor for neurotransmitter detection (a$\mathrm{C}^{7,8}$ and ta- $\mathrm{C}^{7,9,10,11,12,13}$ ). Due to the smoothness of these films and the inert nature of carbon, these materials are less susceptible for biological fouling than metals.

For example, diamond-like carbon resisted microbial attachment in static conditions compared to titanium, tantalum ${ }^{14},{ }^{15},{ }^{16}$ and ta-C resisted protein attachment compared to platinum ${ }^{17}$. The sensitivity of ta-C is usually not high enough for biological applications, but functionalization of the ta-C surface with different carbon allotropes, such as carbon nanotubes and nanofibers or nanodiamonds (ND), have shown great potential for the electrochemical detection of different biomolecules, such as DA, glutamate and ascorbic acid ${ }^{18}$. For example, functionalized NDs coated on ta-C decreased the detection 
limit for DA by three orders of magnitude [from $10 \mu \mathrm{M}$ to $50 \mathrm{nM}$ ] in comparison to ta- $\mathrm{C}^{19}$. Similarly, NDs on boron doped diamond significantly enhanced ionic currents of outer-sphere redox probe (ferrocene methanol), compared to bare $\mathrm{BDD}^{20}$. Pyrolytic carbons (PyC) are a group of nanographitic thin film materials. Large densities of edge-plane sites and oxygenated functionalities on PyC make it an ideal candidate for electrochemical sensor applications ${ }^{21}$. Moreover, PyC enables DA detection in the physiologically relevant range $(50 \mathrm{~nm}-1 \mu \mathrm{M})^{22,23}$ and PyC has dopaminergic properties, i.e. promotes neural stem cell differentiation to dopaminergic phenotype ${ }^{24}$, which makes PyC a highly interesting material for DA sensors.

In a previous research on the electro-oxidation of DA on the unmodified surfaces of five different classes of carbon electrodes (glassy carbon, oxygen-terminated polycrystalline boron-doped diamond (BDD), edge plane pyrolytic graphite, basal plane pyrolytic graphite, and the basal surface of highly oriented pyrolytic graphite (HOPG)), the least susceptible material to DA surface fouling was found to be polycrystalline BDD, which also showed sluggish DA reaction kinetics, while HOPG, which gave the best voltammetric signal to DA, was very susceptible to blocking by dopaminergic products ${ }^{25}$. Another study suggest that carbon nanotube fiber (CNTF) microelectrode is less susceptible for DA fouling than a traditional carbon fiber $(\mathrm{CF})$ micro-electrode due to a decreased binding affinity of the insulating film to CNTF surface ${ }^{26}$. Moreover, the detection of DA in complex biological environments have been investigated. The research indicates that hydrogenation of carbon electrodes has been proposed to minimize fouling during DA detection in vivo ${ }^{27}$ and BDD generally exhibits the better performance in biologically fouling environments than glassy carbon ${ }^{28}$.

\section{Experimental Section}

\section{Substrate fabrication}

Sample fabrication details are provided as supplementary material and the more detailed description of the a-C deposition process can be found from ${ }^{8}$, for ta-C and ND from ${ }^{19}$, and that of PyC from ${ }^{29}$.

Amorphous carbon (a-C) films with varying oxygen or hydrogen content were deposited by closed-field unbalanced magnetron sputtering. a-C O2, a-C H2 and a-C H12 refer to oxygenated or hydrogenated a$\mathrm{C}$ samples, where hydrogen or oxygen inflow was kept at 2 (a-C O2 and H2) or 12 (a-C H12) sccm during the deposition process.

The ta-C sample were prepared on p-type conductive Si substrates $(0.001-0.002 \Omega \mathrm{cm}$, Ultrasil, USA). First $20 \mathrm{~nm}$ of Ti adhesion layer was deposited by direct current magnetron sputter followed by $7 \mathrm{~nm}$ taC film deposited by pulsed filtered cathodic vacuum arc (p-FCVA).

Two types of functionalized NDs: zeta-positive $\mathrm{ND}_{\text {andante }}$ with amino and carboxyl functional groups and zeta-positive hydrogen terminated $\mathrm{ND}_{\mathrm{H}}$ (Carbodeon uDiamond $\AA$, Carbodeon, Vantaa, Finland) were investigated.

For PyC coating, SU-8 resist using a BLE photoresist spinner was spin coated on silicon wafers and soft baked on a hot plate at up to $85^{\circ} \mathrm{C}$, exposed to UV light for 8 seconds (flood exposure), and post-baked on a hot plate. Pyrolysation was carried out in continuous nitrogen flow in a tube furnace at $900^{\circ} \mathrm{C}$ for 4 hours. The thickness of the resin layer was $13.3 \pm 0.4 \mu \mathrm{m}$ and the thickness of the pyrolyzed layer $2.4 \pm$ $0.1 \mu \mathrm{m}$.

The coated $\mathrm{Si}$ wafers were cut to $1 \mathrm{~cm} \times 1 \mathrm{~cm}$ pieces, which were then contacted to $\mathrm{Cu}$ slabs. For CV experiments, a circular area was defined with a Polytetrafluoroethylene tape (Irpola Oy, Finland) and for SECM measurements the samples were placed on the SECM measurement cell, where an O-ring defines a circular area. 


\section{XPS}

X-ray photoelectron spectroscopy (AXIS Ultra, Kratos Analytical at Aalto Biomaterials Center) was utilized for surface chemical characterization. Elemental carbon to oxygen ratios in the surface region were determined from wide spectra, and the amount of oxygen functional groups bonded to carbon was evaluated from peak-fitted $\mathrm{C}$ 1s high-resolution regions. Additionally, oxygen and nitrogen high resolution regions ( $\mathrm{O} 1 \mathrm{~s}$ and $\mathrm{N} 1 \mathrm{~s})$ were acquired. Wide spectra were collected using $1 \mathrm{eV}$ step and 80 $\mathrm{eV}$ pass energy and high-resolution spectra using $0.1 \mathrm{eV}$ step, $20 \mathrm{eV}$ pass energy.

All spectra were collected using monochromatic Al Ka x-ray source at $100 \mathrm{~W}$ and with neutralization in the case of charging. Samples were pre-evacuated overnight in vacuum $<10^{-5} \mathrm{~Pa}$. Analysis chamber vacuum was $<10^{-6} \mathrm{~Pa}$ during measurements. Spectra for each sample were collected from at least three locations (analysis area $\sim 400 \times 800 \mu \mathrm{m}$, depth less than $10 \mathrm{~nm}$ ). Filter paper $(100 \%$ cellulose, Whatman) was used as in situ reference and for binding energy scale calibration $(\mathrm{CO}=286.7 \mathrm{eV}, \mathrm{C}-\mathrm{C}=285.0)^{30}$, 31 . Data fitting, atomic composition ratio calculations and charge correction was done using CasaXPS software (v. 2.3.18). Peak-fitting to the $\mathrm{C}$ 1s high-resolution region was done using equally wide full width half maximum (FWHM) Gaussian lines for each oxygen functional group ${ }^{31}$.

\section{Cyclic voltammetry}

Cyclic voltammetry was carried out with a Gamry Reference 600 potentiostat in a three-electrode cell. The reference was an $\mathrm{Ag} / \mathrm{AgCl}$ electrode $(+0.199 \mathrm{~V}$ vs SHE, Radiometer Analytical) and a platinum wire was used as the counter electrode.

Surfaces were subjected to fouling in $1 \mathrm{mM}$ DA in phosphate buffered saline (pH 7.4) for 10 cycles with $50 \mathrm{mV} / \mathrm{s}$, followed by cleaning in $0.15 \mathrm{M} \mathrm{H}_{2} \mathrm{SO}_{4}$ for 10 cycles with $50 \mathrm{mV} / \mathrm{s}$. After cleaning, the DA measurement was repeated. Samples were rinsed twice in $\mathrm{dH}_{2} \mathrm{O}$ between the different electrolytes.

All the solutions were deoxygenated with argon for at least 15 minutes prior to measurements and blanketed during measurements in order to avoid DA self-polymerization.

\section{Scanning electrochemical microscopy}

Scanning electrochemical microscopy (SECM) measurements were carried out using CHI910B scanning electrochemical microscope ( $\mathrm{CH}$ Instruments). $10 \mu \mathrm{m}$ platinum wires sealed in glass were used as the working electrode, an $\mathrm{Ag} / \mathrm{AgCl}$ electrode served as a reference electrode and a platinum wire as a counter electrode. Approach curves and SECM images were recorded using a steady state voltage of $400 \mathrm{mV}$ for the working electrode and $1 \mathrm{mM} \mathrm{FcMeOH}$ in $0.15 \mathrm{M} \mathrm{H}_{2} \mathrm{SO}_{4}$ was used as a mediator. No potential was applied at the surface during approach curves or SECM imaging.

Substrate surfaces were the carbon electrodes under investigation. SECM approach curves and imaging were performed for untreated samples, then subsequent to cycling in DA (fouled) and subsequent to cycling in $\mathrm{H}_{2} \mathrm{SO}_{4}$ (cleaned). Fouling consisted of cycling in $1 \mathrm{mM} \mathrm{DA}$ in phosphate buffer (pH 7.4) for 10 cycles with either $50 \mathrm{mV} / \mathrm{s}, 400 \mathrm{mV} / \mathrm{s}$ or $1 \mathrm{~V} / \mathrm{s}$. After cycling $50 \mathrm{mV} / \mathrm{s}$, the surfaces were subjected to cleaning in $0.15 \mathrm{M} \mathrm{H}_{2} \mathrm{SO}_{4}$ with $50 \mathrm{mV} / \mathrm{s}$ twice (cleaning 1: 10 cycles, cleaning 2: 10 more cycles). Samples were rinsed twice in $\mathrm{dH}_{2} \mathrm{O}$ between the different electrolytes. All the solutions were deoxygenated with argon for at least 15 minutes prior to measurements.

SECM experimentation consists of recording approach curves where the normalized current $I=\mathrm{i} / \mathrm{i}_{\text {inf }}$ is plotted versus the normalized distance $L=d / a$, where $i$ is the current at the tip electrode (radius a) localized at a distance $d$ from the substrate, $i_{\text {inf }}$ is the steady-state current when the tip is at an infinite 
distance from the substrate. The approach rate was $2 \mu \mathrm{m} \mathrm{s}^{-1}$. The fittings between experimental and theoretical curves were done following C. Lefrou's approximations ${ }^{32}$ based on Bard-Mirkin's formalism, where tips parameters (a and $\mathrm{R} / \mathrm{G}$ ) were determined independently from approach curves of an insulator sample. A dimensionless rate constant $\kappa=\mathrm{k}_{\text {eff }} \mathrm{a} / \mathrm{D}$, where $\mathrm{k}_{\text {eff }}$ is an apparent heterogeneous charge transfer constant between the mediator in solution and the substrate and D diffusion constant, was obtained from the theoretical approach curves. SECM imaging was recorded in feedback mode. Approach curves and imaging were performed in $1 \mathrm{mM} \mathrm{FcMeOH}$ before DA fouling, after DA fouling and after cleaning in $\mathrm{H}_{2} \mathrm{SO}_{4}$ and repeated three times in each step at different locations of the sample. The presented $\kappa$-values are average of the three measurements \pm standard deviation. $\mathrm{H}_{2} \mathrm{SO}_{4}$ was obtained from Merck or Fisher Scientific, all other chemicals from Sigma-Aldrich.

\section{Results and Discussion}

\section{XPS}

The elemental composition of the samples is presented in Table 1. The oxygen functionalities of a-C surface increased with oxygen inflow during deposition (a-C O2 sample), whereas hydrogen inflow increased the relative amount of $\mathrm{CC}$ bonding (a-C H2 and a-C H12 samples). $\mathrm{ND}_{\text {andante }}$ and $\mathrm{ND}_{\mathrm{H}}$ present similar surface chemistries. However, the amount of oxygen as well as COO bonding is higher on $\mathrm{ND}_{\text {andante }}$ indicating carboxyl functionalities. XPS did not verify difference in amino functionalities between $\mathrm{ND}_{\text {andante }}$ and $\mathrm{ND}_{\mathrm{H}}$, possibly due to the small amount (1.1-1.2\%) of nitrogen in the samples. As for comparison, we have earlier functionalized ta-C surfaces with 3-Triethoxysilylpropylamine (APTES) in order to achieve amino-functionalized surface ${ }^{10}$. According to XPS analysis the amount of $\mathrm{N}(1 \mathrm{~s})$ on APTES functionalized surfaces was $1.2 \%$, which is the same amount as observed here on $\mathrm{ND}_{\text {andante. }}$

PyC consists $98.5 \%$ of carbon and only small amount of functional groups exists, which is the main difference to other carbon electrode materials investigated in this study.

\section{Electrochemistry}

The degree of fouling of different carbon electrodes with different terminations was determined using $\mathrm{CV}$ and SECM approach curves and imaging. DA exhibited quasi-reversible behaviour with sluggish electron transfer kinetics on all of the tested electrode materials, except on a-C H12, where the behaviour was irreversible. Based on the voltammograms of DA fouling, it is evident that polydopamine forms on all of the electrode materials. With all scanning rates $(50 \mathrm{mV} / \mathrm{s}, 400 \mathrm{mV} / \mathrm{s}$ and $1000 \mathrm{mV} / \mathrm{s})$, the oxidation peak current magnitude decreased significantly over consecutive scans during cycling. Figure 2 shows the voltammograms of DA fouling with $50 \mathrm{mV} / \mathrm{s}$ and the repeated DA measurement after cleaning in $\mathrm{H}_{2} \mathrm{SO}_{4}$, and Table 2 summarizes the respective changes observed in peak separation $(\Delta \mathrm{Ep})$ and oxidation peak current $\left(\mathrm{I}_{\mathrm{po}}\right)$. When cycling with $50 \mathrm{mV} / \mathrm{s}$, the oxidation peak current decreased on average by $28 \%$ by the second cycle, while $\Delta \mathrm{E}_{\mathrm{P}}$ increased on average by $78 \%$ by $10^{\text {th }}$ cycle. This indicates formation of an insulating layer on the surface, which is confirmed by the approach curves and calculated $\kappa$-values for $\mathrm{FcMeOH}$ (Table 3). Initially all of the materials but a-C $\mathrm{H} 12$ showed good electron transport properties with positive feedback $(\kappa>2$ for FcMeOH). After the substrates had been subjected to 10 cycles in $1 \mathrm{mM}$ DA using scanning speed of $50 \mathrm{mV} / \mathrm{s}$, negative feedback $(\kappa<1$ for $\mathrm{FcMeOH}$ ) was recorded for all materials but $\mathrm{ND}_{\text {andante, }}$ confirming the formation of an insulating layer.

Interestingly, a positive feedback $(\kappa>2.5$ for $\mathrm{FcMeOH})$ was recorded for $\mathrm{ND}_{\text {andante }}$ even after 10 cycles in $1 \mathrm{mM} \mathrm{DA}$, indicating that the polydopamine layer is either nonuniform or thinner than on the other 
tested materials. The fouling behaviour is not linked to DA detection capability as spray-coated $\mathrm{ND}_{\text {andante }}$ and $\mathrm{ND}_{\mathrm{H}}$ demonstrated similar behaviour with the linear range of $500 \mathrm{nM}-1 \mathrm{mM}$ and sensitivities of 0.161 and $0.172 \mathrm{~A} \mathrm{M}^{-1} \mathrm{~cm}^{-2}$, respectively ${ }^{19}$. It is possible that the heterogeneous surface functionalities containing amino-groups protect $\mathrm{ND}_{\text {andante }}$ surface from the formation of uniform $\mathrm{DA}$ layer. We have previously observed that spray-coated amino functionalized nanodiamonds $\left(\mathrm{ND}_{\mathrm{amine}}\right)$ on ta-C did not produce oxidation or reduction peaks even at high concentrations of DA ${ }^{19}$. This could be due to electrostatic repulsion between DA and protonated amine groups as, at physiological pH, DA exists mostly as a cation ${ }^{2}$. Heterogeneous surface functionalities containing amino-functionalities may prevent DA adsorption and therefore protect surfaces from forming thick and uniform polydopamine layer while at the same time the carboxyl-functionalities help to promote electron transfer and allow the DA to be detected. SECM images confirm the heterogeneous surface kinetics on NDs, but it seems possible that the electrochemical properties follow the topographical features of the sample to a certain degree. However, after DA fouling $(50 \mathrm{mV} / \mathrm{s}), \mathrm{ND}_{\text {andante }}$ represents current range from negative $\left(\mathrm{i} / \mathrm{i}_{\text {inf }}<\right.$ 1) to positive $\left(\mathrm{i} / \mathrm{i}_{\text {inf }}>1\right)$ feedback, indicating true heterogeneity of the surface. The size of the different regions of conductivity is approximately $20 \mu \mathrm{m}$.

As mentioned, a negative feedback $(\kappa<1$ for $\mathrm{FcMeOH})$ was recorded for other tested materials subsequent to DA fouling. However, some differences were observed. All of the a-C surfaces became more insulating $(\kappa<0.5$ for $\mathrm{FcMeOH})$ than ta-C or PyC $(\kappa=0.8 \mathrm{FcMeOH})$. The chemical inertness of the surface arising from the $\mathrm{sp}^{3}$ nature of the surface may protect ta-C from fouling as severely as a-C surfaces. This is in agreement with previous reports stating that the extensive $\mathrm{sp}^{3}$ structure results in a decrease in the adsorption of certain fouling agents ${ }^{33,34}$. Moreover, the initial $\kappa$-value measured in $\mathrm{FcMeOH}$ for PyC is higher than for other materials, which may explain why the $\kappa$-value remains higher even after fouling.

Different a-C samples showed minor differences in their fouling behaviour. Based on the calculated $\kappa$ values, a-C O2 $(\kappa=0.22)$ becomes slightly more insulating than a-C ref $(\kappa=0.38)$, which is again more insulating than a-C H2 $(\kappa=0.47)$. This is possibly due to the interactions of oxygen functional groups and DA. The hydrophilic functional groups may increase the adsorption of the polar dopaminechrome molecules. Similar lower fouling resistance towards polar molecules on O-terminated carbon surface was observed in a study of norepinephrine and theophylline electrochemistry on graphene oxide and reduced graphene oxide modified glassy carbon surfaces ${ }^{35}$. Note, that fouling resistance is essentially depended on the fouling agent. In general, with biological fouling agents (proteins), O-termination of carbon surfaces is considered to increase the fouling resistance due to the increased surface hydrophilicity, which minimises the tendency of proteins to unfold and foul by hydrophobic mechanisms ${ }^{36}$.

Subsequent to DA fouling, we examined the recovery capacity of the carbon surfaces. Cycling in $\mathrm{H}_{2} \mathrm{SO}_{4}$ effectively removed the insulating polydopamine layer from all the surfaces but PyC. Figure 2 shows the repeated DA measurement and Table 3 the $\kappa$-values measured in $\mathrm{FcMeOH}$, which both are recovered close to the original level for other materials except for PyC. For PyC, the repeated DAmeasurement shows $50 \%$ larger $\Delta \mathrm{Ep}$ with $12 \%$ smaller oxidation current compared to the initial DA response and the $\kappa$-value measured in $\mathrm{FcMeOH}$ is recovered only to some degree (to 2.4 as the original was 3.1). This behaviour can be caused by the adsorption of DA on PyC surfaces. The shape of the PyC voltammogram with steep oxidation and reduction peaks indicates that adsorption has a role in the overall kinetics (Figure 3). However, the adsorption can still be considered "weak" as there is no separate peak for the adsorbed species (energy difference is relatively small between dissolved and adsorbed species). Owing to adsorption, PyC also demonstrates the largest oxidation and reduction peak currents of the tested materials, which is due to the fact that both soluble and adsorbed DA contribute to the reaction. Thus, there are more reactants near the electrode than there would be without adsorption. Indeed, on PyC the DA reaction kinetics is both diffusion and adsorption defined ${ }^{29}$. 
Furthermore, the large drop in $\mathrm{I}_{\mathrm{po}}$ by the $2^{\text {nd }}$ cycle $\left(2^{\text {nd }}\right.$ cycle $63 \%$ of the $1^{\text {st }}$ on PyC, while it remains $>$ $70 \%$ on other tested electrode materials) with hardly any effect on $\mathrm{E}_{\mathrm{po}}(4 \mathrm{mV}$ for PyC) indicate a formation of a (probably thin) layer on the surface during the first cycle. Moreover, physisorbed or chemisorbed monolayers of DA are catalytic toward DA oxidation and reduction ${ }^{6}$, which can explain the fastest electron transfer kinetics of the tested materials $\left(\Delta \mathrm{E}_{\mathrm{P}}=183 \mathrm{mV}\right)$. Furthermore, on PyC, the shape of the return curve is significantly different from the other tested materials. The other carbon electrodes demonstrate similar behaviour to $\mathrm{ND}_{\text {andante, }}$ with a drop in the current (at about $400 \mathrm{mV}$ ) prior to reduction, whereas PyC demostrates very steep reduction peak (Figure 3). On PyC, an additional reduction peak appears at $-315 \mathrm{mV}$ on the first scan corresponding to the reduction of dopaminechrome (DAC) to leucodopaminechrome (LDAC). On the subsequent scan, the corresponding oxidation of leucodopaminechrome can be seen at $-170 \mathrm{mV}$. Similar features can be seen on a-C ref, a-C O2 and a-C $\mathrm{H} 2$, but not on ta-C or NDs within the tested cycling window. The adsorption of DA (and probably also some subsequent reaction products) on $\mathrm{PyC}$ also most likely causes the observed only partial recovery of the surface properties of PyC after cycling in sulfuric acid, which is also in contrast with the other investigated materials. The XPS measurement showed, that PyC consist of highly homogeneous surface of C-C and C-H bonding (98.5\%), which may explain the DA adsorption and subsequent DA fouling on PyC.

The differences observed in DA fouling possibly originate from DA reaction kinetics. DA is an innersphere redox couple that is likely to react at specific adsorption sites ${ }^{37}$. These sites favor redox reactions and consequently they may be exposed to a higher level of dopaminequinone, which then takes part to the fouling cascade. Subsequently, these sites are the most probable to be subjected to electrochemical fouling. It can be concluded that electrodes that facilitate redox reactions through enhanced adsorption are more sensitive to fouling than the ones with more sluggish kinetics. The PyC surface shows very sharp DA oxidation peak we have shown that the reaction kinetics both diffusion and adsorption defined $^{29}$. Consequently, PyC surface is the most sensitive to DA fouling. ND andante seems to show sluggish DA kinetics (Figure 3: wider $\mathrm{CV}$, lower current density, high $\mathrm{E}_{\mathrm{p}}$ and $\mathrm{E}_{\mathrm{po}}$ ) but resist fouling well. This resistance can be due to amino functionalities, which do not facilitate DA reactions.

The fouling behavior may have been affected by the $\mathrm{CV}$ cycling parameters. All of the materials were scanned between $-350 \mathrm{mV}$ and $800 \mathrm{mV}$, except a-C H12, which was scanned from $-350 \mathrm{mV}$ to $1.6 \mathrm{~V}$. PyC has the lowest DA oxidation potential $(305 \mathrm{mV})$ of the tested materials, and consequently the scan limit is highest with respect to the oxidation potential. By scanning the potential to higher values than the oxidation peak, adsorbed species on the electrode surface undergo further chemical and electrochemical reactions ${ }^{12}$. As a result, polydopamine film structure, which cannot be as effectively removed by cleaning in $\mathrm{H}_{2} \mathrm{SO}_{4}$, may be formed.

Even though the DA voltammogram and the calculated $\kappa$-values for FcMeOH indicate surface recovery, the SECM images (Figure 4) confirm that there are remnants of the DA (in a size range of ten $\mu \mathrm{m}$ to a few dozen micrometers) still present as the surface conductivity is more heterogeneous than that of pristine surface.

In Figure 4, we utilized constant scale for all of the plots in order to improve comparison of the samples. It is evident that the current range drops significantly after DA fouling and recovers again after cleaning in $\mathrm{H}_{2} \mathrm{SO}_{4}$, except for a-C $\mathrm{H} 12$ which is initially insulating. The unscaled version of the Figure 4 is provided as supplementary material to better visualize different features of the surfaces.

With higher CV scanning rates in DA, the passivation is less significant. A clear reduction peak of dopaminequinone and consequently higher $\mathrm{I}_{\text {red }} / \mathrm{I}_{\mathrm{ox}}$ ratio is observed, indicating that the intramolecular cyclization does not have time to occur, instead dopaminequinone is reduced back to DA. This is in agreement with a previous experiment showing that the difference in the reversibility of the dopamine redox reaction is obvious at different scan rates: the $\mathrm{I}_{\mathrm{red}} / \mathrm{I}_{\mathrm{ox}}$ relationship of DA is 0.77 for $1000 \mathrm{mV} \mathrm{s}^{-1}$ and only 0.11 for $50 \mathrm{mV} \mathrm{s}^{-1} 12$. Consequently, cycling DA at $1000 \mathrm{mV} / \mathrm{s}$ results in no changes in $\Delta \mathrm{Ep}$, 
indicating that no continuous layer of polydopamine is formed on the surface. The approach curves measured in $\mathrm{FcMeOH}$ support this, as no significant changes are observed in the calculated $\kappa$-values (Table 3) for a substrate treated in this way, confirming the effective electron transfer. However, as the oxidation current drops on average by $44 \%$ by $10^{\text {th }} \mathrm{CV}$ cycle, it is clear that DA fouling occurs on the surfaces and the electroactive surface area is reduced. This is supported by the subsequent SECM image (Figure 5), which show the formation of islands with decreased conductivity. Cycling DA with the slower scan rate of $400 \mathrm{mV} / \mathrm{s}$ results in the increase of $\Delta \mathrm{Ep}$ on average by $9 \%$ and decrease of the oxidation current by $55 \%$ by $10^{\text {th }}$ cycle. The change in $\Delta \mathrm{Ep}$ indicates that uniform DA layer is starting to form.

SECM proved to be an effective tool for evaluating fouling of the carbon substrate electrode. The use of DA as a mediator in SECM directly is challenging, as the ultra microelectrode utilized in SECM fouls in the presence of DA as well. However, by utilizing another redox probe subsequent to substrate fouling, we showed that we can "quantify" the thickness of the insulating film with SECM approach curves and discriminate between continuous layers and islands of the polydopamine with SECM images. It is possible that polydopamine, which forms clumpses ${ }^{38}$, is not strongly adhered to the substrate and the clumpses delaminate when taken out from liquid environment. Moreover, the melanin-like polymeric molecules are of $\sim 3.8 \AA$ in size, and consequently the detection of a monolayer would be difficult with microscopic methods such as scanning electron microscopy or atomic force microscopy. The supplementary materials shows examples of the studied surfaces before and after DA fouling observed with scanning electron microscopy and atomic force microscopy. No polydopamine layer is observed. In conclusion, in-situ techniques, such as SECM, in-situ scanning tunneling microscopy or in situ atomic force microscopy, may be required to reliably asses DA fouling.

A high concentration of DA $(1 \mathrm{mM})$ was deliberately employed to accelerate the fouling phenomenon associated with DA oxidation in order to evaluate the lifetime of the electrodes. The DA concentrations in vivo are significantly lower $\left(5-700 \mathrm{nM}^{39}\right)$ than what was tested here $(1 \mathrm{mM})$. Therefore, similar rapid fouling will not occur in vivo. Moreover, physiological reducing agents, such as ascorbic acid, reduce dopaminequinone back to its original form before the intracyclization can occur ${ }^{40}$. In addition to judicious choice of electrode material, the scanning parameters affect severity of fouling. Here, little fouling was observed with scanning speeds of $400 \mathrm{mV} / \mathrm{s}$ or $1000 \mathrm{mV} / \mathrm{s}$. Fast scan cyclic voltammetry can even further reduce electrode fouling ${ }^{41,42}$ by outrunning the side reactions that lead to fouling products. Alternatively, fouling may also be decreased by using high anodic-cathodic potentials between voltammetric scans 41,42 . Moreover, biological environment can affect the electrochemical fouling as different proteins can either increase or decrease the rate of electrode fouling ${ }^{43}$. For example, cysteine residues reduce the severity of DA electrochemical fouling ${ }^{44}$.

Table 4 summarizes the electrochemical properties. Based on our previous research, the reaction kinetic towards outer sphere probes is comparable between all the tested materials and all of them showing reversible or quasi-reversible reaction kinetics, except for a-C $\mathrm{H} 12$, which shows sluggish reaction kinetics. Reaction kinetics towards $\mathrm{DA}$ is significantly faster $\left(\Delta \mathrm{E}_{\mathrm{p}} 44.6 \mathrm{mV}\right)$ on PyC than on the other tested materials $\left(\Delta \mathrm{E}_{\mathrm{p}}>124 \mathrm{mV}\right)$ and it can detect significantly lower concentrations of DA (50 mM vs 1 $\mu \mathrm{M})$ than ND or ta-C. Detection limits for the a-C samples has not been defined.

\section{Conclusions}

We evaluated the degree of fouling of different carbon electrodes with different terminations using CV and SECM approach curves and imaging. Polydopamine was formed on all of the materials, which was observed both as a drop in DA oxidation current as well as increasing $\Delta \mathrm{Ep}$. When cycling DA for 10 cycles with $50 \mathrm{mV} / \mathrm{s}$, an insulating layer of polydopamine was formed on all of the materials except for $\mathrm{ND}_{\text {andante, }}$ as verified by the approach curves measured in $\mathrm{FcMeOH}$. We showed that heterogeneous 
modification of carbon electrodes with carboxyl-amine functionalities offers protection against formation of an insulating polydopamine layer, while retaining the ability to detect DA. The advantages of the heterogenous termination are likely due to the electrostatic repulsion between aminofunctionalities and DA. With higher scanning speeds $(400 \mathrm{mV} / \mathrm{s}$ or $1000 \mathrm{mV} / \mathrm{s})$ formation of an insulating layers was not evident on the surfaces from CV measurements, but SECM images confirmed that some fouling of the surface was still taking place. Moreover, we showed that the conductivity of the surfaces as well as the response towards DA on all materials but $\mathrm{PyC}$ was recovered close to the original performance level subsequent to cleaning the surfaces in $\mathrm{H}_{2} \mathrm{SO}_{4}$. The recovery capacity of PyC electrode was inferior possibly due to stronger adsorption of DA on the surface. In conclusion, polydopamine formed on all the tested materials, but the severity of fouling is affected by the surface properties of the material. SECM proved to be an effective tool for evaluating electrode fouling as we can "quantify" the thickness of the insulating film with SECM approach curves and discriminate between continuous layers and islands of the polydopamine with SECM images.

\section{Acknowledgements}

Academy of Finland (E.P. grant \#274670, T.L. grants \#285015 and \#285526) and Orion Research Foundation (E.P.) are acknowledged for funding. We acknowledge the provision of facilities and technical support by Aalto University at OtaNano - Nanomicroscopy Center (Aalto-NMC) and the cleanroom facilities of Micronova. Niklas Wester and Joonas J. Heikkinen from the Department of Chemistry and Materials Science, School of Chemical Engineering, Aalto University are acknowledged for ta-C and PyC coating, respectively. Leena-Sisko Johansson from the Department of Bioproducts and Biosystems, School of Chemical Engineering, Aalto University is acknowledged for help with the XPS measurements.

\section{Supporting Information}

Information about substrate fabrication; Microscopy of the surface before and after DA fouling; Unscaled figure of the fouled surfaces.

Supporting information.pdf

\section{References}

1. Beaulieu, J.; Gainetdinov, R.R. Pharmacol Rev. 2011, 63, 182-217.

2. Wisniewski, N.; Reichert, M. Colloids Surf B Biointerfaces. 2000, 18, 197-219.

3. Liu, Y.; Ai, K.; Lu, L. Chem Rev. 2014, 114, 5057-5115.

4. Luczak, T. Electrochim Acta. 2008, 53, 5725-5731.

5. Hong, S.; Na, Y.S.; Choi, S.; Song, I.T; Kim, W.Y.; Lee, H. Adv Funct Mater. 2012, 22, 4711-4717.

6. Duvall, S.H.; McCreery, R.L. J Am Chem Soc. 2000, 122, 6759-6764.

7. Kaivosoja, E.; Sainio, S.; Lyytinen, J.; Palomäki, T., Kim, S.I.; Han, J.G.; Koskinen, J. Surf Coat

Technol. 2014, 259, 33-38.

8. Palomäki, T.; Wester, N.; Johansson, L.S; Laitinen, M.; Juang, H.; Arstila, K.; Sajavaara, T.; Han, J.G.; Koskinen, J.; Laurila, T. Electrochim Acta. 2016, 220, 137-145.

9. Kaivosoja, E.; Berg, E.; Rautiainen, A.; Palomäki, T.; Koskinen, J.; Paulasto-Kröckel, M.; Laurila T. Proc Annu Int Conf IEEE Eng Med Biol Soc EMBS. 2013, 632-634.

10. Kaivosoja, E.; Tujunen, N.; Jokinen, V.; Protopopova, V.; Heinilehto, S.; Koskinen, J., Laurila, T. Talanta. 2015, 141, 175-181. 
11. Laurila, T.; Rautiainen, A.; Sintonen, S.; Jiang, H.; Kaivosoja, E.; Koskinen, J. Mater Sci Eng C. 2014, 34, 446-454.

12. Palomäki, T.; Chumillas, S.; Sainio, S.; Protopopova, V.; Kauppila, M.; Koskinen, J.; Climent, V.; Feliu, J.M.; Laurila, T. Diamond Relat Mat. 2015, 59, 30-39.

13. Palomäki, T.; Wester, N.; Caro, M.A.; Sainio, S.; Protopopova, V.; Koskinen, J.; Laurila, T. Electrochim Acta. 2017, 225, 1-10.

14. Myllymaa, K.; Levon, J.; Tiainen, V.M.; Myllymaa, S.; Soininen, A.; Korhonen, H.; Kaivosoja, E.; Lappalainen, R.; Konttinen, Y.T. Colloids Surf B Biointerfaces. 2013, 101, 290-297.

15. Kaivosoja, E.; Virtanen, S.; Rautemaa, R.; Lappalainen, R.; Konttinen, Y.T. Eur Cell Mater. 2012, 24, 60-73.

16. Levon, J.; Myllymaa, K.; Kouri, V.P,; Rautemaa, R.; Kinnari, T.; Myllymaa, S.; Konttinen, Y.T.; Lappalainen, R. J Biomed Mater Res Part A. 2010, 92, 1606-1613.

17. Tujunen, N.; Kaivosoja, E.; Protopopova, V.; Valle-Delgado, J.J.; Österberg, M.; Koskinen, J.; Laurila, T. Mater Sci Eng C. 2015, 55, 70-78.

18. Laurila, T.; Sainio, S.; Caro, M. Prog Mater Sci. 2017, 88, 499-594.

19. Peltola, E.; Wester, N.; Holt, K.B.; Johansson, L.S.; Koskinen, J.; Myllymäki, V.; Laurila, T.

Biosens Bioelectron. 2017, 88, 273-282.

20. Gupta, S.; McDonald, B.; Carrizosa, S. B. J. Electron. Mater. 2017, 46, 4512-4526.

21. Keeley, G.P.; McEvoy, N.; Kumar, S.; Peltekis, N.; Mausser, M.; Duesberg, G.S. Electrochem Commun. 2010, 12, 1034-1036.

22. Zen, J.; Chen, P. Anal. Chem. 1997, 69, 5087-5093.

23. Wightman, R.M.; May, L.J.; Michael, A.C. Anal. Chem. 1988, 60, 769-779.

24. Amato, L.; Heiskanen, A.; Caviglia, C.; Shah, F.; Zór, K.; Skolimowski, M.; Madou, M.;

Gammelgaard, L.; Hansen, R.; Seiz, E.G.; Ramos, M.; Moreno, T.R.; Martínez-Serrano, A.; Keller,

S.S.; Emnéus, J. Adv Funct Mater. 2014, 24, 7042-7052.

25. Patel, A.N.; Tan, S.Y.; Miller, T.S.; Macpherson, J.V.; Unwin, P.R. Anal. Chem. 2013, 85, $11755-11764$.

26. Harreither, W.; Trouillon, R.; Poulin, P.; Neri, W.; Ewing, A.G.; Safina, G. Anal.Chem. 2013, 85, 7447-7453.

27. Chandra, S.; Miller, A.D.; Bendavid, A.; Martin, P.J.; Wongt, D.K.Y. Anal.Chem. 2014, 86, 2443-2450.

28. Trouillon, R.; O’Hare, D. Electrochimica Acta 2010, 55, 6586-6595

29. Peltola, E.; Heikkinen, J.J.; Sovanto, K.; Sainio, S.; Aarva, A.; Franssila, S.; Jokinen, V.; Laurila, T. Journal of Materials Chemistry B, in press DOI: 10.1039/C7TB02469J

30. Johansson, L.S.; Campbell, J.M. Surf. Interface Anal. 2004, 36, 1018-1022.

31. Beamson, G.; Briggs, D. High Resolution XPS of Organic Polymers: The Scienta ESCA300

Database, 1992.

32. Cornut, R.; Lefrou, C. J Electroanal Chem. 2008, 621, 178-184.

33. McCreery, R.L. Chem. rev. 2008, 108, 2646-2687.

34. Shin, D.; Tryk, D.A.; Fujishima, A.; Merkoci, A.; Wang, J. Electroanalysis 2005, 17, 305-311.

35. Raj, M.A.; John, S.A. Anal. Methods 2014, 6, 2181-2188.

36. Hanssen, B.L.; Siraj, S.; Wong, D.K.Y. Rev. Anal. Chem. 2016, 35, 1-28.

37. Bard, A.J. J. Am. Chem. Soc. 2010, 132, 7559-7567.

38. Clancy, C. M.; Nofsinger, J. B.; Hanks R. K.; Simon, J. D. J. Phys. Chem. B 2000, 104, 7871-7873.

39. Robinson, D.L.; Venton, B.J.; Heien, M.L.A.V.; Wightman, R.M. Clin Chem. 2003, 49, 1763-1773.

40. Sternson, A.W.; McCreery, R.; Feinberg, B; Adams, R.N. J Electroanal Chem. 1973, 46, 313-321.

41. Jackson, B.P.; Dietz, S.M.; Wightman, R.M. Anal Chem. 1995, 67, 1115-1120.

42. Swamy, B.E.K.; Venton, B.J. Analyst. 2007, 132, 876-884.

43. Fagan-Murphy A.; Watt, F.; Morgan, K.A.; Patel, B.A. J Electroanal Chem. 2012, 684, 1-5. 
44. Harreither, W.; Trouillon, R.; Poulin, P.; Neri, W.; Ewing, A.G.; Safina, G. Electrochim Acta. 2016, 210, 622-629.

45. Palomäki, T.; Wester, N.; Han J.G.; Sajavaara, T.; Johansson, L.S.; Koskinen, J.; Laurila, T.; 19th topical meeting of the international society of electrochemistry 2016, s1-065.

Table 1: XPS results showing the elemental composition and carbon bonding of the samples. Columns 1-3 are calculated from wide spectrum and columns 4-8 from high-resolution scan.

\begin{tabular}{|c|c|c|c|c|c|c|c|c|}
\hline & C (1s) & $O(1 s)$ & N (1s) & $\mathrm{CC}^{*}$ & CC* & C-O & $\mathrm{C}=\mathbf{O}$ & COO \\
\hline a-C ref & $91.1 \pm 0.2$ & $8.0 \pm 0.1$ & $0.4 \pm 0.1$ & \multicolumn{2}{|c|}{$79.4 \pm 0.1$} & $13.6 \pm 0.1$ & $4.1 \pm 0.1$ & $2.9 \pm 0.1$ \\
\hline a-C O2 & $87.5 \pm 0.4$ & $11.6 \pm 0.3$ & $0.5 \pm 0.1$ & \multicolumn{2}{|c|}{$75.9 \pm 0.1$} & $15.2 \pm 0.1$ & $5.3 \pm 0.1$ & $3.5 \pm 0.1$ \\
\hline a-C H2 & $91.2 \pm 0.2$ & $7.9 \pm 0.1$ & $0.3 \pm 0.1$ & \multicolumn{2}{|c|}{$81.3 \pm 0.2$} & $12.4 \pm 0.1$ & $3.7 \pm 0.1$ & $2.6 \pm 0.1$ \\
\hline a-C H12 & $89.8 \pm 0.1$ & $9.7 \pm 0.1$ & $0.2 \pm 0.1$ & \multicolumn{2}{|c|}{$84.4 \pm 0.3$} & $10.6 \pm 0.2$ & $3.4 \pm 0.1$ & $1.6 \pm 0.1$ \\
\hline ta-C & $89.8 \pm 0.1$ & $8.9 \pm 0.1$ & $0.8 \pm 0.1$ & $28.7 \pm 1.3$ & $57.9 \pm 1.4$ & $7.5 \pm 0.1$ & $3.7 \pm 0.2$ & $2.1 \pm 0.1$ \\
\hline $\mathbf{N D}_{\mathrm{H}}$ & $93.9 \pm 0.4$ & $4.8 \pm 0.3$ & $1.1 \pm 0.1$ & & $58.8 \pm 0.2$ & $37.6 \pm 0.1$ & $3.4 \pm 0.1$ & $0.2 \pm 0.1$ \\
\hline ND $_{\text {andante }}$ & $93.3 \pm 0.2$ & $5.4 \pm 0.2$ & $1.2 \pm 0.1$ & & $59.0 \pm 0.4$ & $38.5 \pm 0.5$ & $1.9 \pm 0.2$ & $0.5 \pm 0.1$ \\
\hline PyC & $98.5 \pm 0.1$ & $1.5 \pm 0.1$ & $0.1 \pm 0.1$ & $74.4 \pm 1.7$ & $16.1 \pm 1.8$ & \# & \# & $\#$ \\
\hline
\end{tabular}

* a-C samples were fitted with one carbon peak, whereas ta-C, NDs and PyC were fitted with two carbon peaks (first being more "graphitic" and second being more $\mathrm{sp}^{3}$-carbon)

\# Functional groups exists, but determination of the exact amounts is not unambiguous.

Table 2: Peak separation $(\Delta \mathrm{Ep})$, and oxidation peak voltage (Epo) and current (Ipo) for DA during DA fouling $\left(1^{\text {st }}, 2^{\text {nd }}\right.$ and $10^{\text {th }}$ cycle) and after the subsequent $\mathrm{H}_{2} \mathrm{SO}_{4}$ cleaning. Cycling speed $50 \mathrm{mV} \mathrm{s}^{-1}$.

\begin{tabular}{|c|c|c|c|c|c|c|c|c|c|c|c|c|}
\hline & \multicolumn{4}{|c|}{$\Delta E p(m V)$} & \multicolumn{4}{|c|}{ Epo $(m V)$} & \multicolumn{4}{|c|}{ Ipo $\left(\mu \mathrm{A} \mathrm{cm}^{-2}\right)$} \\
\hline Cycle & $1 \mathrm{st}$ & 2nd & 10th & After $\mathrm{H}_{2} \mathrm{SO}_{4}$ & $1 \mathrm{st}$ & $2 n d$ & 10th & After $\mathrm{H}_{2} \mathrm{SO}_{4}$ & $1 \mathrm{st}$ & 2nd & 10th & After $\mathrm{H}_{2} \mathrm{SO}_{4}$ \\
\hline $\mathrm{a}-\mathrm{C}$ ref & 215 & 270 & 496 & 267 & 308 & 357 & 505 & 331 & 249 & 180 & 139 & 243 \\
\hline $\mathrm{a}-\mathrm{C} \mathrm{O} 2$ & 352 & 322 & 531 & 279 & 427 & 403 & 560 & 343 & 231 & 180 & 141 & 253 \\
\hline $\mathrm{a}-\mathrm{C} \mathrm{H} 2$ & 240 & 288 & 490 & 269 & 329 & 373 & 528 & 340 & 233 & 168 & 123 & 235 \\
\hline a-C H12 & $*$ & * & $*$ & $*$ & 1390 & 1422 & \# & 1400 & 173 & 140 & \# & 182 \\
\hline ta-C & 366 & 393 & 534 & 400 & 438 & 461 & 574 & 457 & 211 & 157 & 133 & 216 \\
\hline $\mathrm{ND}_{\mathrm{H}}$ & 374 & 438 & 603 & 375 & 367 & 424 & 574 & 408 & 253 & 185 & 150 & 274 \\
\hline $\mathrm{ND}_{\text {andante }}$ & 387 & 471 & 672 & 422 & 468 & 526 & 686 & 417 & 222 & 163 & 141 & 182 \\
\hline $\mathrm{PyC}$ & 183 & 190 & 285 & 276 & 305 & 309 & 367 & 376 & 347 & 219 & 157 & 307 \\
\hline
\end{tabular}

*) No reduction peak, $\Delta$ Ep could not be defined

\#) No peak definable at 10th cycle, at 7th cycle Epo $1546 \mathrm{mV}$ and $137 \mu \mathrm{A} \mathrm{cm}^{-2}$.

Table 3: $\kappa$-values for $\mathrm{FcMeOH}$ defined from the approach curves for pristine surface, after $1 \mathrm{mM} \mathrm{DA}$ fouling with $50 \mathrm{mV} \mathrm{s}^{-1}$ or $1 \mathrm{~V} \mathrm{~s}^{-1}$ and after subsequent cleaning in $0.15 \mathrm{M} \mathrm{H}_{2} \mathrm{SO}_{4}$.

\begin{tabular}{|l|l|l|l|l|l|l|l|l|}
\hline $\boldsymbol{\kappa}(\mathbf{F c M e O H})$ & a-C ref & a-C O2 & a-C H2 & a-C H12 & ta-C & $\mathbf{N D}_{\mathbf{H}}$ & $\mathbf{N D}_{\text {andante }}$ & PyC \\
\hline Pristine surface & $2.2 \pm 0.1$ & $2.29 \pm 0.03$ & $2.27 \pm 0.03$ & $0.02 \pm 0.01$ & $2.33 \pm 0.05$ & $2.17 \pm 0.06$ & $3.1 \pm 0.3$ & $3.1 \pm 0.1$ \\
\hline DA $50 \mathrm{mV} / \mathrm{s}$ & $0.38 \pm 0.04$ & $0.22 \pm 0.05$ & $0.47 \pm 0.05$ & $0.03 \pm 0.00$ & $0.81 \pm 0.08$ & $0.30 \pm 0.06$ & $2.5 \pm 0.1$ & $0.8 \pm 0.3$ \\
\hline $\mathrm{H}_{2} \mathrm{SO}_{4}, 10$ cycles & $2.0 \pm 0.2$ & $1.9 \pm 0.2$ & $2.2 \pm 0.2$ & $0.04 \pm 0.01$ & $2.2 \pm 0.1$ & $1.6 \pm 0.9$ & $2.5 \pm 0.1$ & $2.4 \pm 0.1$ \\
\hline $\mathrm{H}_{2} \mathrm{SO}_{4}, 20$ cycles & $2.07 \pm 0.01$ & $2.0 \pm 0.1$ & $2.2 \pm 0.1$ & $0.05 \pm 0.01$ & $2.3 \pm 0.08$ & $2.9 \pm 0.5$ & $3.7 \pm 0.9$ & $2.7 \pm 0.2$ \\
\hline \multicolumn{9}{|l|}{$\mid$} \\
\hline Pristine surface & $2.2 \pm 0.1$ & $2.6 \pm 0.1$ & $2.6 \pm 0.4$ & $0.03 \pm 0.00$ & $2.5 \pm 0.5$ & $2.4 \pm 0.5$ & $2.9 \pm 0.8$ & $3.0 \pm 0.2$ \\
\hline DA 1 V/s, 10 cycles & $2.2 \pm 0.6$ & $2.5 \pm 0.1$ & $2.2 \pm 0.2$ & $0.04 \pm 0.00$ & $2.5 \pm 0.5$ & $2.1 \pm 0.2$ & $2.8 \pm 0.1$ & $2.9 \pm 0.1$ \\
\hline
\end{tabular}

Table 4: Advantages and disadvantages of the tested samples.

\begin{tabular}{|l|l|l|l|l|l|}
\hline & $\begin{array}{l}\Delta \mathrm{E}_{\mathrm{p}}(\mathrm{mV}) \text { for } \\
\text { outer sphere } \\
\text { redox probe }\end{array}$ & $\begin{array}{l}\Delta \mathrm{E}_{\mathrm{p}}(\mathrm{mV}) \text { for } \\
100 \mu \mathrm{M} \mathrm{DA}\end{array}$ & $\begin{array}{l}\text { Lowest measured } \\
\mathrm{DA} \\
\text { concentrations }\end{array}$ & DA fouling & DA recovery \\
\hline a-C ref & $59.8^{\mathrm{a}, \mathrm{b}}$ & $124^{\mathrm{b}}$ & ${ }^{\mathrm{e}}$ & ++ & ++ \\
\hline $\mathrm{a}-\mathrm{C} \mathrm{O} 2$ & $62.8^{\mathrm{a}, \mathrm{b}}$ & $150^{\mathrm{b}}$ & ${ }^{\mathrm{e}}$ & ++ & ++ \\
\hline $\mathrm{a}-\mathrm{C} \mathrm{H} 2$ & 58.6 & $128^{\mathrm{b}}$ & ${ }^{\mathrm{e}}$ & ++ & ++ \\
\hline $\mathrm{a}-\mathrm{C} \mathrm{H12}$ & 789 & $1142^{\mathrm{b}}$ & ${ }^{\mathrm{e}}$ & ++ & ++ \\
\hline ta-C & $57.1^{\mathrm{a},} \mathrm{b}$ & $369^{\mathrm{d}}$ & $10 \mu \mathrm{M}^{\mathrm{f}}$ & ++ & ++ \\
\hline $\mathrm{ND}_{\mathrm{H}}$ & $62^{\mathrm{c}, \mathrm{d}}$ & $192^{\mathrm{d}}$ & $1 \mu \mathrm{M}$ & ++ & ++ \\
\hline $\mathrm{ND}_{\text {andante }}$ & $64^{\mathrm{c}, \mathrm{d}}$ & $198^{\mathrm{d}}$ & $1 \mu \mathrm{M}$ & partial & ++ \\
\hline $\mathrm{PyC}$ & $62.8^{\mathrm{a}, \mathrm{b}}$ & $44.6^{\mathrm{b}}$ & $50 \mathrm{nM}$ & ++ & partial \\
\hline
\end{tabular}


${ }^{\mathrm{a}} \mathrm{Ru}{ }^{\mathrm{b}} 100 \mathrm{mV} \mathrm{s}^{-1 \mathrm{c}} \mathrm{FcMeOH}{ }^{\mathrm{d}} 50 \mathrm{mV}^{-1}$ e detection limits have not been defined ${ }^{\mathrm{f}}$ Defined on ta-C film grown on Pt film $\Delta \mathrm{E}_{\mathrm{p}}$ and lowest measured DA concentrations has been previously reported: a-C and a-C $\mathrm{O}_{2}{ }^{8}$, a-C H2 and a-C $\mathrm{H} 12^{45}$, ta-C $^{11,12}, \mathrm{ND}^{19}$ and $\mathrm{PyC}^{29}$

\section{Figure caption}

Figure 1: First steps of the formation of polydopamine.

Figure 2: $1 \mathrm{mM}$ DA fouling with $50 \mathrm{mV} / \mathrm{s}$. Gray curve shows the 10 fouling cycles and dotted black curve the repeated DA measurement after 10 cleaning cycles in $0.15 \mathrm{M} \mathrm{H}_{2} \mathrm{SO}_{4}$.

Figure 3: $1^{\text {st }}$ (gray) and $2^{\text {nd }}$ (dotted black) DA fouling cycles on $\mathrm{ND}_{\text {andante }}$ and PyC.

Figure 4: Pristine surfaces (first column) and surfaces after cycling in $1 \mathrm{mM} \mathrm{DA}$ with $50 \mathrm{mV} / \mathrm{s}$ (second column) and after subsequent cleaning in $\mathrm{H}_{2} \mathrm{SO}_{4} 10$ cycles (third column) or 20 cycles (fourth column). Each graph is $50 \mu \mathrm{m} \times 50 \mu \mathrm{m}$ and the scale bar indicates relative current $\mathrm{i} / \mathrm{i}_{\text {inf }}$.

Figure 5: Examples of SECM images recorded in FcMeOH before and after 10 cycles of DA cycling with $1 \mathrm{~V} \mathrm{~s}^{-1}$ on a-C and ta-C surfaces. Each graph is $50 \mu \mathrm{m} \times 50 \mu \mathrm{m}$. Scale is kept constant for each sample. 
For TOC only

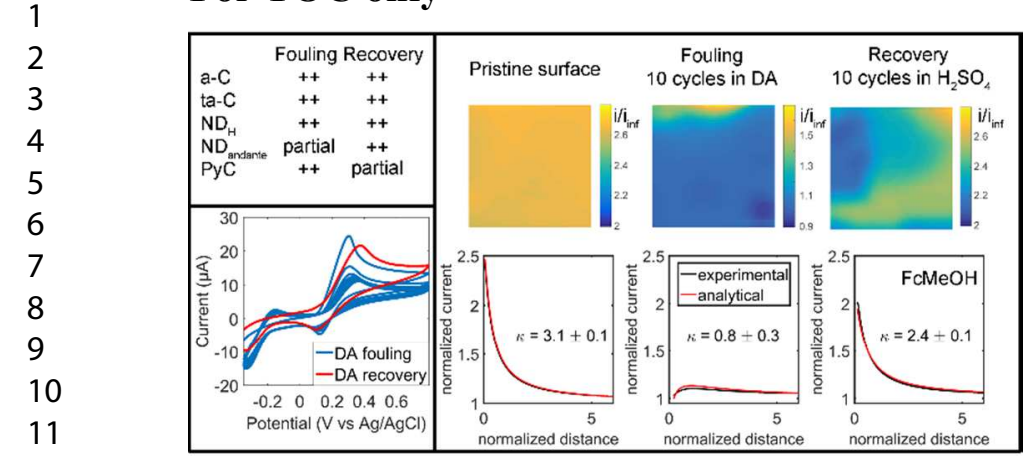




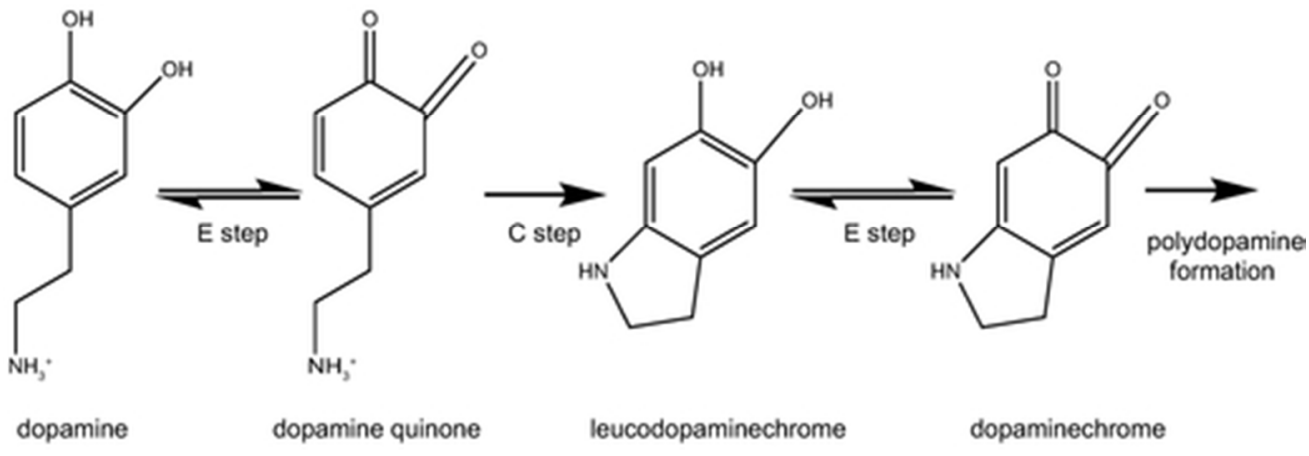

Figure 1

$43 \times 14 \mathrm{~mm}(300 \times 300$ DPI $)$ 

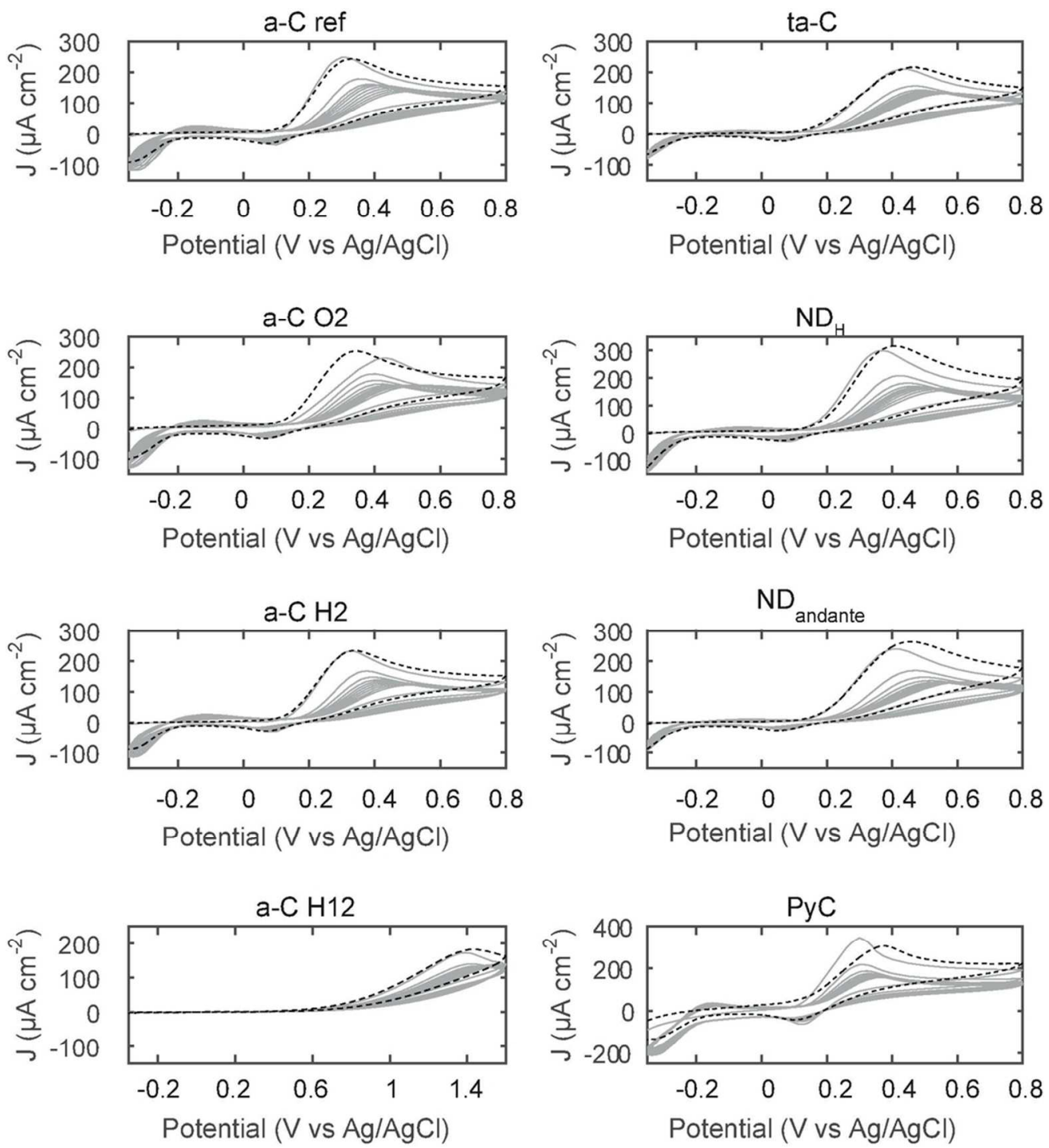

Figure 2

$92 \times 101 \mathrm{~mm}(300 \times 300 \mathrm{DPI})$ 

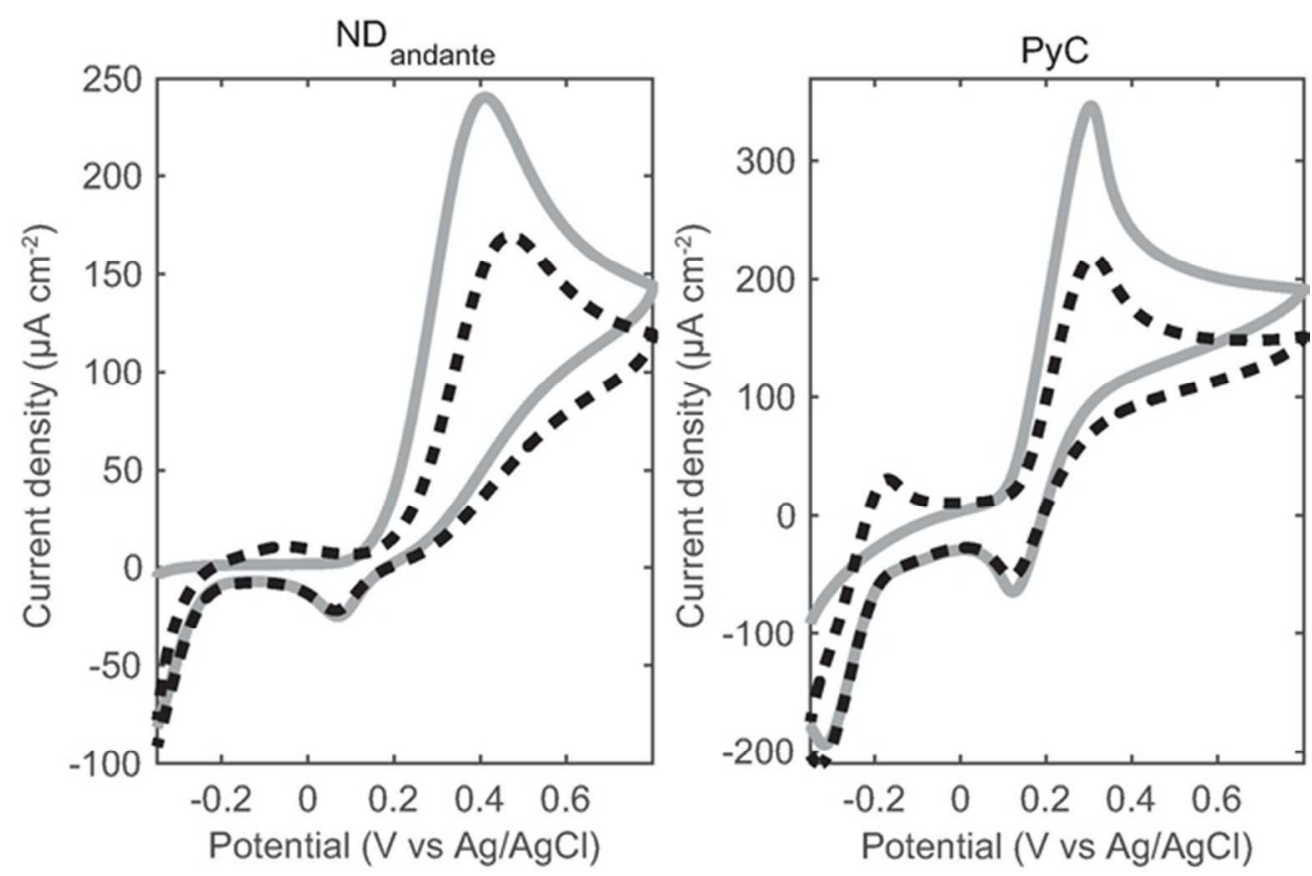

Figure 3

$55 \times 36 \mathrm{~mm}(300 \times 300$ DPI $)$ 


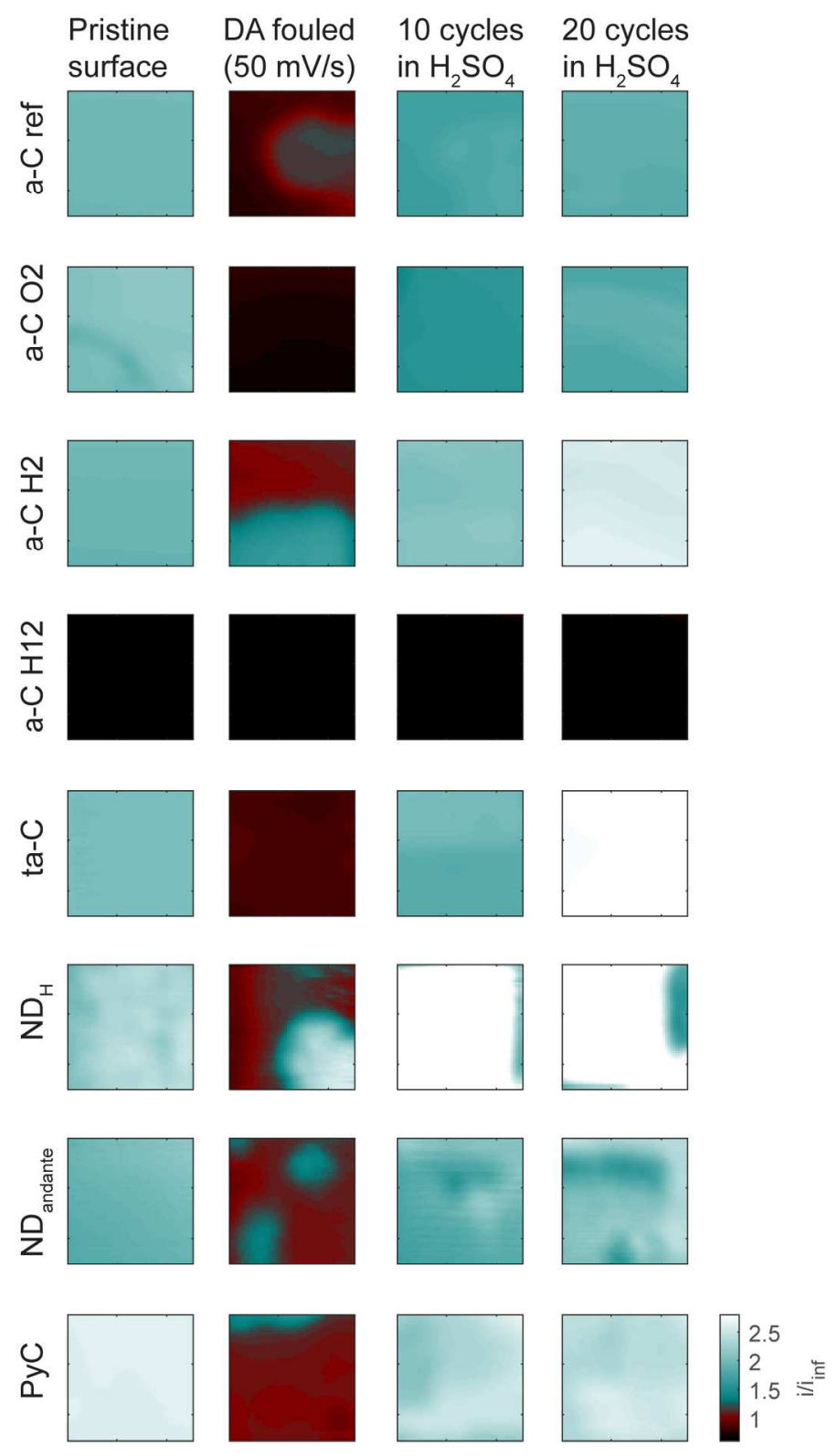

Figure 4

$113 \times 197 \mathrm{~mm}(300 \times 300 \mathrm{DPI})$ 

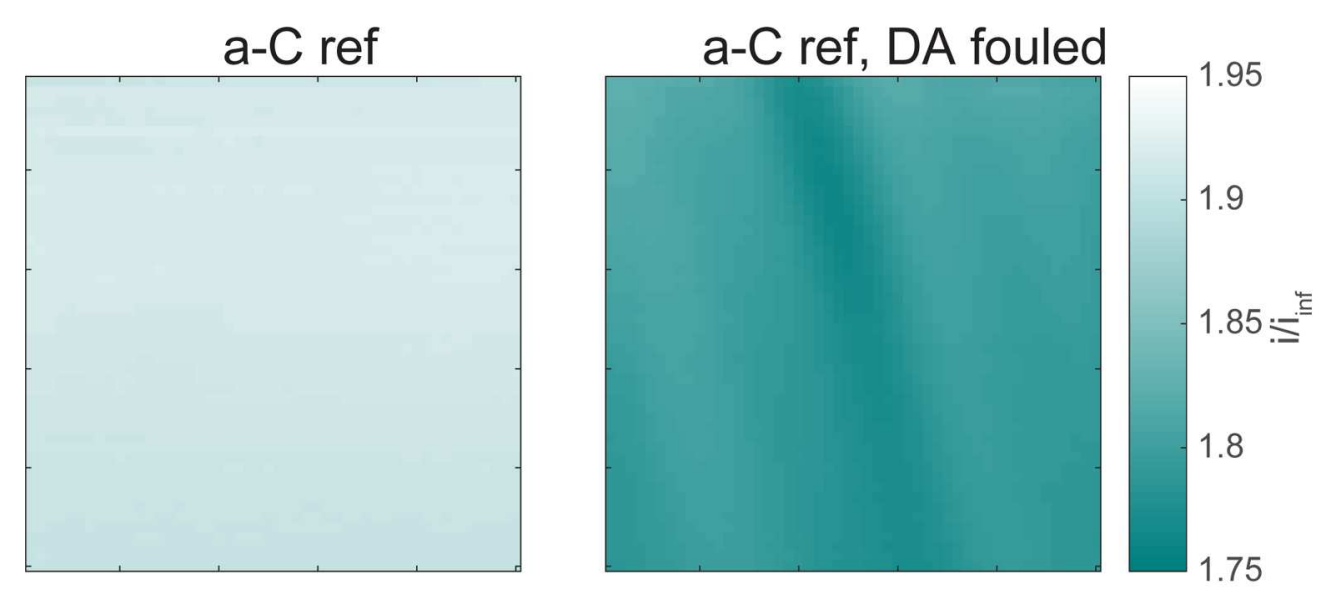

\section{ta-C}

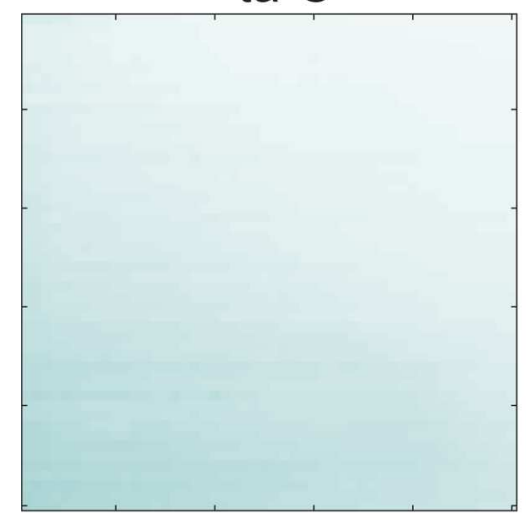

ta-C, DA fouled

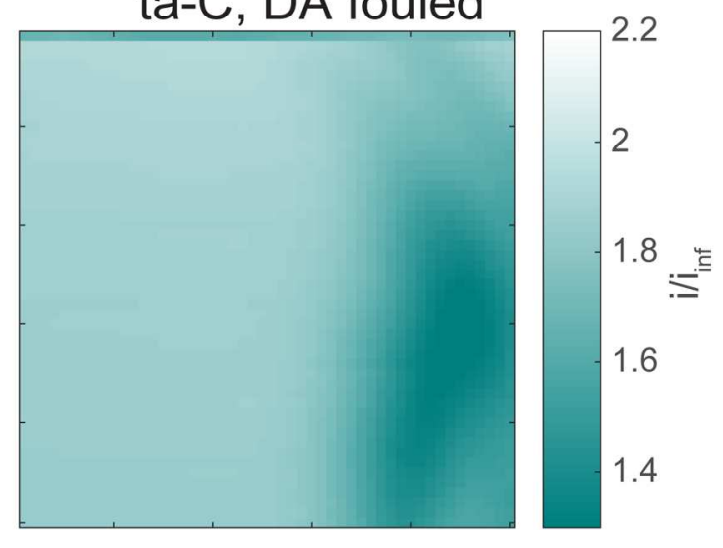

Figure 5

$162 \times 144 \mathrm{~mm}(300 \times 300 \mathrm{DPI})$ 